\title{
ANALISIS EFEKTIVITAS BIAYA PENGGUNAAN ANTIBIOTIK CEFTRIAXONE DAN AMPICILIN PADA PASIEN PNEUMONIA ANAK RAWAT INAP DI RSUD RADEN MATTAHER JAMBI TAHUN 2018
}

\author{
COST EFFECTIVENESS ANALYSIS OF ANTIBIOTICS USING \\ CEFTRIAXONE AND AMPICILIN IN PNEUMONIA PATIENTS IN \\ INpatient CHILDREN AT RADEN MATTAHER JAMBI Hospital,
} 2018

\author{
Rasmaladewi ${ }^{1}$, Mukhlis Sanuddin ${ }^{1}$, Maratus Shaleha ${ }^{1^{*}}$ \\ ${ }^{1}$ Program Studi Farmasi, STIKES Harapan Ibu Jambi \\ Koresponding Penulis: maratusshaleha123@gmail.com
}

\begin{abstract}
ABSTRAK
Di Indonesia karakteristik penduduk dengan diagnosa ISPA tertinggi terjadi pada kelompok usia 1-4 tahun (25,8\%). Pneumonia merupakan salah satu penyebab dari $16 \%$ kematian pada balita, diperkirakan sebanyak 920.136 balita di tahun 2015. Menurut WHO pada tahun 2013 menyebutkan dari 6,3 juta anak berusia dibawah 5 tahun yang meninggal karena disebabkan oleh infeksi adalah sebesar 51,8\%. Antibiotik merupakan golongan obat yang paling banyak digunakan terkait dengan banyaknya penyakit infeksi bakteri seperti pneumonia. Penelitian ini bertujuan untuk mengetahui efektivitas biaya penggunaan antibiotik pada pasien pneumonia di RSUD Raden Mattaher Jambi. Penelitian ini merupakan penelitian non eksperimental dengan pengumpulan data dilakukan secara retrospektif, sampel diambil pada tahun 2018. Analisis data dilakukan dengan metode CEA. Hasil penelitian didapatkan bahwa nilai ACER Ceftriaxone lebih tinggi yaitu sebesar 8.135,78 dibandingkan dengan nilai ACER ampicillin sebesar 6.644,49. Semakin rendah nilai ACER dan semakin tinggi efektivitas terapi maka semakin efektif biaya terapi antibiotik tersebut, sehingga dapat disimpulkan bahwa terapi menggunakan antibiotik Ampicilin adalah obat yang paling cost-effective untuk terapi pengobatan pasien pneumonia di RSUD Raden Mattaher Jambi.
\end{abstract}

Kata Kunci: CEA, Antibiotik, Pneumonia, ACER

\section{ABSTRACK}

In Indonesia the characteristics of the population with the highest ARI diagnosis occur in the 1-4 year age group (25.8\%). Pneumonia is one of the causes of $16 \%$ of deaths in infants, an estimated 920,136 toddlers in 2015. According to the WHO in 2013 said that from 6.3 million children under the age of 5 years who died due to infection were $51.8 \%$. Antibiotics are the most widely used class of drugs associated with many bacterial infectious diseases such as pneumonia. This study aims to determine the costeffectiveness of antibiotic use in pneumonia patients at Raden Mattaher Jambi Hospital. This research is a non-experimental study with data collection conducted 
Journal of Healthcare Technology and Medicine Vol. 6 No. 2 Oktober 2020

Universitas Ubudiyah Indonesia

e-ISSN : 2615-109X

retrospectively, samples were taken in 2018. Data analysis was performed using the CEA method. The results showed that the ACER Ceftriaxone value was higher at 8,135.78 compared to the ACER ampicillin value of 6,644.49. The lower the ACER value and the higher the effectiveness of therapy, the more effective the cost of antibiotic therapy is, so it can be concluded that therapy using ampicillin antibiotics is the most cost-effective drug for the treatment of pneumonia patients in Raden Mattaher Hospital in Jambi.

Keywords: CEA, Antibiotics, Pneumonia, ACER

\section{PENDAHULUAN}

Di Indonesia karakteristik penduduk dengan diagnosa ISPA yang tertinggi terjadi pada kelompok usia 1 sampai 4 tahun (25,8\%) (Musdalipah, et al., 2018), berdasarkan jenis kelamin tidak ada perbedaan antara perempuan dengan laki-laki, namun penyakit ISPA ini lebih banyak dialami oleh masyarakat dengan indeks pendapatan menengah kebawah (Riskesdas, 2013). Pneumonia merupakan penyakit kedua tertinggi yang dapat menyebabkan kematian terutama pada balita . Di Indonesia terdapat sekitar 568.146 balita yang terserang pneumonia, dengan kematian diperkirakan sebanyak 920.136 balita di tahun 2015 (Nalang et al., 2018)

Analisis efektivitas biaya adalah suatu metode farmakoekonomi yang dapat digunakan untuk menilai serta memilih program atau pengobatan yang terbaik pada beberapa pilihan terapi dengan tujuan yang sama. Metode ini perlu dilakukan perhitungan ACER dan ICER. Cara tersebut dilakukan untuk mengetahui pengobatan mana yang lebih cost efektive dari kedua alternatif pengobatan yang dipilih (Musdalipah et al., 2018).

Pasien pneumonia balita di RSUD Raden Mattaher Jambi mendapat kan terapi antibiotik pada pengobatannya, namun dari semua jenis antibiotik yang digunakan belum diketahui antibiotik mana yang lebih cost-effective. Berdasarkan hal tersebut dilakukan penelitian untuk mengetahui efektivitas biaya penggunaan antibiotik pada pasien pneumonia di rawat inap RSUD Raden Mattaher Jambi yang berfungsi untuk mengetahui biaya penggunaan antibiotik pada pasien pneumonia.

\section{'METODE PENELITIAN}

Penelitian yang digunakan adalah penelitian non eksperimental dengan rancangan deskriptif dan pengambilan data secara retrospektif berdasarkan data rekam medik dan data biaya langsug pasien yang telah menjalani pengobatan di bangsal anak RSUD Raden 
Journal of Healthcare Technology and Medicine Vol. 6 No. 2 Oktober 2020

Universitas Ubudiyah Indonesia

e-ISSN : 2615-109X

Mattaher Jambi. Sampel pada penelitian ini adalah pasien anak penderita pneumonia yang mendapatkan terapi antibiotik Ceftriaxon atau Ampicillin. Data disajikan dalam bentuk tabel.

\section{HASIL DAN PEMBAHASAN}

Tabel 1. Karakteristik Pasien Berdasarkan Usia

\begin{tabular}{lcc}
\hline \multicolumn{1}{c}{ Usia } & Jumlah Pasien & Persentase (\%) \\
\hline $0-1$ bulan & 1 & 3,2 \\
\hline 1 bulan -1 tahun & 15 & 48,38 \\
\hline 1 tahun -4 tahun & 11 & 35,48 \\
\hline 4 tahun - 14 tahun & 4 & 12,90 \\
\hline Total & 31 & 100 \\
\hline
\end{tabular}

Sumber : Database RSUD Raden Mattaher Tahun 2018

Tabel 2. Karakteristik Pasien Berdasarkan Jenis Kelamin

\begin{tabular}{lcc}
\hline \multicolumn{1}{c}{ Jenis Kelamin } & Jumlah Pasien & Persentase (\%) \\
\hline Perempuan & 13 & 41,94 \\
\hline Laki-laki & 18 & 58,06 \\
\hline Total & 31 & 100 \\
\hline
\end{tabular}

Sumber : Database RSUD Raden Mattaher Tahun 2018

Tabel 3. Persentase Penggunaan Antibiotik Pada Pasien Pneumonia Anak Tahun 2018

\begin{tabular}{|l|c|c|}
\hline \multicolumn{1}{|c|}{ Antibiotik } & Jumlah Pasien & Persentase (\%) \\
\hline Ceftriaxone & 17 & 54,83 \\
\hline Ampicillin & 14 & 45,17 \\
\hline Total & 31 & 100 \\
\hline
\end{tabular}


Journal of Healthcare Technology and Medicine Vol. 6 No. 2 Oktober 2020

Universitas Ubudiyah Indonesia

e-ISSN : 2615-109X

Tabel 4. Kadar Leukosit pada pasien Pneumonia tahun 2018

\begin{tabular}{|c|c|c|c|c|c|}
\hline No. & No. RM & Antibiotik & Leukosit Awal & Leukosit Akhir & Keterangan \\
\hline 1 & $876 \times x \times$ & Ceftriaxone & $12.000 \mathrm{sel} / \mathrm{mm} 3$ & $8.000 \mathrm{sel} / \mathrm{mm} 3$ & $\mathrm{~N}$ o $\mathrm{r}$ m a 1 \\
\hline 2 & $696 \times x \times$ & Ceftriaxone & $15.000 \mathrm{sel} / \mathrm{mm} 3$ & $8.000 \mathrm{sel} / \mathrm{mm} 3$ & 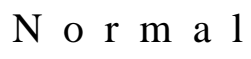 \\
\hline 3 & $899 \times \times x$ & Ceftriaxone & $12.000 \mathrm{sel} / \mathrm{mm} 3$ & $7.000 \mathrm{sel} / \mathrm{mm} 3$ & 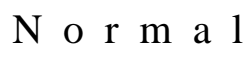 \\
\hline 4 & $900 \times \times x$ & Ceftriaxone & $13.000 \mathrm{sel} / \mathrm{mm} 3$ & $5.000 \mathrm{sel} / \mathrm{mm} 3$ & 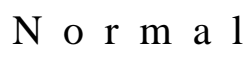 \\
\hline 5 & $902 \times \times x$ & Ceftriaxone & $14.000 \mathrm{sel} / \mathrm{mm} 3$ & $8.000 \mathrm{sel} / \mathrm{mm} 3$ & $\mathrm{~N}$ o \\
\hline 6 & $355 \times \times x$ & Ceftriaxone & $11.000 \mathrm{sel} / \mathrm{mm} 3$ & $6.000 \mathrm{sel} / \mathrm{mm} 3$ & $\mathrm{~N}$ o \\
\hline 7 & $894 \times x \times$ & Ceftriax one & $13.000 \mathrm{sel} / \mathrm{mm} 3$ & $15.000 \mathrm{sel} / \mathrm{mm} 3$ & Meningkat \\
\hline 8 & $883 \times \times x$ & Ceftriaxone & $14.000 \mathrm{sel} / \mathrm{mm} 3$ & $8.000 \mathrm{sel} / \mathrm{mm} 3$ & $\mathrm{~N}$ o \\
\hline 9 & $887 \times x \times$ & Ceftriaxone & $15.000 \mathrm{sel} / \mathrm{mm} 3$ & $10.000 \mathrm{sel} / \mathrm{mm} 3$ & $\mathrm{~N}$ o $\mathrm{r}$ m a 1 \\
\hline 10. & $888 \times x \times$ & Ceftriax one & $13.000 \mathrm{sel} / \mathrm{mm} 3$ & $15.000 \mathrm{sel} / \mathrm{mm} 3$ & Meningkat \\
\hline 11. & $839 \times \times x$ & Ceftriaxone & $13.000 \mathrm{sel} / \mathrm{mm} 3$ & $6.000 \mathrm{sel} / \mathrm{mm} 3$ & $\mathrm{~N}$ o $\begin{array}{rllll} & \mathrm{m} & \mathrm{a} & 1\end{array}$ \\
\hline 12. & $899 \times \times x$ & Ceftriaxone & $13.000 \mathrm{sel} / \mathrm{mm} 3$ & $7.000 \mathrm{sel} / \mathrm{mm} 3$ & $\mathrm{~N}$ o $\mathrm{r}$ m a 1 \\
\hline 13. & $902 \times x \times$ & Ceftriax one & $15.000 \mathrm{sel} / \mathrm{mm} 3$ & $8.000 \mathrm{sel} / \mathrm{mm} 3$ & $\mathrm{~N}$ o $\mathrm{r}$ m a 1 \\
\hline 14. & $898 \times x \times$ & Ceftriaxone & $14.000 \mathrm{sel} / \mathrm{mm} 3$ & $15.000 \mathrm{sel} / \mathrm{mm} 3$ & Meningkat \\
\hline
\end{tabular}


Journal of Healthcare Technology and Medicine Vol. 6 No. 2 Oktober 2020 Universitas Ubudiyah Indonesia e-ISSN : 2615-109X

\begin{tabular}{|c|c|c|c|c|c|}
\hline 15. & $899 \times \times x$ & Ceftriaxone & $13.000 \mathrm{sel} / \mathrm{mm} 3$ & $14.000 \mathrm{sel} / \mathrm{mm} 3$ & Meningkat \\
\hline 16. & $878 \times x \times$ & Ceftriax one & $15.000 \mathrm{sel} / \mathrm{mm} 3$ & $8.000 \mathrm{sel} / \mathrm{mm} 3$ & $\mathrm{~N}$ o $\begin{array}{rllll} & \mathrm{m} & \mathrm{a} & \mathrm{l}\end{array}$ \\
\hline 17. & $880 \times x \times$ & Ceftriax one & $14.000 \mathrm{sel} / \mathrm{mm} 3$ & $16.000 \mathrm{sel} / \mathrm{mm} 3$ & Meningkat \\
\hline 18. & $843 \times x \times$ & Ampicilin & $15.000 \mathrm{sel} / \mathrm{mm} 2$ & $8.000 \mathrm{sel} / \mathrm{mm} 3$ & $\mathrm{~N}$ o $\mathrm{r}$ m a 1 \\
\hline 19. & $878 \times x x$ & Ampicilin & $12.000 \mathrm{sel} / \mathrm{mm} 3$ & $14.000 \mathrm{sel} / \mathrm{mm} 3$ & Meningkat \\
\hline 20 . & $868 \times x \times$ & Ampicilin & $12.000 \mathrm{sel} / \mathrm{mm} 3$ & $13.000 \mathrm{sel} / \mathrm{mm} 3$ & $\mathrm{~N}$ o $\quad \mathrm{r}$ m a 1 \\
\hline 21. & $897 \times x \times$ & Ampicilin & $11.000 \mathrm{sel} / \mathrm{mm} 3$ & $8.000 \mathrm{sel} / \mathrm{mm} 3$ & $\mathrm{~N}$ o $\quad \mathrm{r}$ m a 1 \\
\hline 22. & $876 \times x \times$ & Ampicilin & $13.000 \mathrm{sel} / \mathrm{mm} 3$ & $7.000 \mathrm{sel} / \mathrm{mm} 3$ & $\mathrm{~N}$ o $\quad \mathrm{r}$ m a 1 \\
\hline 23. & $884 \times x \times$ & Ampicilin & $14.000 \mathrm{sel} / \mathrm{mm} 3$ & $9.000 \mathrm{sel} / \mathrm{mm} 3$ & $\mathrm{~N}$ o $\quad \mathrm{r} \mathrm{m}$ a 1 \\
\hline 24. & $888 \times x x$ & Ampicilin & $13.000 \mathrm{sel} / \mathrm{mm} 3$ & $6.000 \mathrm{sel} / \mathrm{mm} 3$ & $\mathrm{~N}$ o $\quad \mathrm{r}$ m a 1 \\
\hline 25 . & $896 \times x \times$ & Ampicilin & $13.000 \mathrm{sel} / \mathrm{mm} 3$ & $8.000 \mathrm{sel} / \mathrm{mm} 3$ & 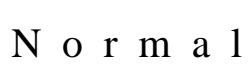 \\
\hline 26. & $894 \times x \times$ & Ampiciln & $14.000 \mathrm{sel} / \mathrm{mm} 3$ & $5.000 \mathrm{sel} / \mathrm{mm} 3$ & $\mathrm{~N}$ o $\mathrm{r}$ m a 1 \\
\hline 27. & $901 \times \times x$ & Ampicilin & $13.000 \mathrm{sel} / \mathrm{mm} 3$ & $7.000 \mathrm{sel} / \mathrm{mm} 3$ & $\mathrm{~N}$ o $\quad \mathrm{r}$ m a 1 \\
\hline 28. & $806 \times \times x$ & Ampicilin & $13.000 \mathrm{sel} / \mathrm{mm} 3$ & $14.000 \mathrm{sel} / \mathrm{mm} 3$ & Meningkat \\
\hline 29. & $899 \times x \times$ & Ampicilin & $15.000 \mathrm{sel} / \mathrm{mm} 3$ & $5.000 \mathrm{sel} / \mathrm{mm} 3$ & 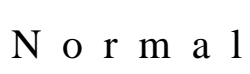 \\
\hline 30. & $902 \times \times x$ & Ampicilin & $14.000 \mathrm{sel} / \mathrm{mm} 3$ & $6.000 \mathrm{sel} / \mathrm{mm} 3$ & $\mathrm{~N}$ or $\mathrm{r}$ m a 1 \\
\hline 31. & $884 \times x \times$ & Ampicilin & $14.000 \mathrm{sel} / \mathrm{mm} 3$ & $7.000 \mathrm{sel} / \mathrm{mm} 3$ & $\mathrm{~N}$ o $\quad \mathrm{r}$ m $\mathrm{a} 1$ \\
\hline
\end{tabular}


Journal of Healthcare Technology and Medicine Vol. 6 No. 2 Oktober 2020

Universitas Ubudiyah Indonesia

e-ISSN : 2615-109X

Sumber : Database RSUD Raden Mattaher Tahun 2018

Tabel 5. Gambaran Biaya Medik Langsung Pasien Pneumonia Anak Tahun 2018

\begin{tabular}{|c|c|c|c|c|c|}
\hline $\begin{array}{c}\text { Terapi } \\
\text { yang } \\
\text { diberikan }\end{array}$ & $\begin{array}{c}\text { Biaya perawatan } \\
\text { dan ruangan }\end{array}$ & $\begin{array}{c}\text { Biaya } \\
\text { laboratorium }\end{array}$ & $\begin{array}{c}\text { Biaya } \\
\text { obat }\end{array}$ & $\begin{array}{c}\text { Biaya } \\
\text { total }\end{array}$ & $\begin{array}{c}\text { Rata } \\
\text { rata } \\
\text { biaya }\end{array}$ \\
\hline Ceftriaxone & 5.607 .000 & 3.791 .000 & 363.800 & 9.761 .800 & 574.223 \\
\hline Ampicillin & 4.725 .000 & 3.122 .000 & 126.000 & 7.973 .000 & 569.500 \\
\hline
\end{tabular}

Tabel 6. Persentase Efektivitas Obat

\begin{tabular}{|l|c|c|c|}
\hline \multicolumn{1}{|c|}{ Antibiotik } & Jumlah Pasien & $\begin{array}{c}\text { Jumlah pasien yang } \\
\text { mencapai target }\end{array}$ & Efektifitas (\%) \\
\hline Ceftriaxone & 17 & 12 & 70,58 \\
\hline Ampicillin & 14 & 12 & 85,71 \\
\hline
\end{tabular}

Tabel 7. Perhitungan ACER penggunaan antibiotik

\begin{tabular}{|l|c|c|c|}
\hline \multicolumn{1}{|c|}{ Antibiotik } & Total biaya (C) & Efektifitas (E) & ACER \\
\hline Ceftriaxone & 574.223 & 70,58 & $8.135,78$ \\
\hline Ampicillin & 569.500 & 85,71 & $6.644,49$ \\
\hline
\end{tabular}

Berdasarkan hasil penelitian yang telah dilakukan, kelompok usia 1 bulan - 1 tahun sebanyak 15 pasien dengan persentase sebesar 48,38\%, usia $1-4$ tahun sebanyak 11 pasien dengan persentase sebesar 35,48\%, selanjutnya kelompok usia $4-14$ tahun sebanyak 4 pasien dengan persentase sebesar 12,90\% dan kelompok usia $0-1$ bulan sebanyak 1 pasien dengan persentase 3,2\%. Kelompok usia $0-1$ tahun merupakan usia yang rentan terserang pneumonia, hal ini terjadi karena sistem imun yang belum sempurna. Sistem imun adalah sistim koordinasi respons biologik yang tujuannya untuk melindungi integritas dan identitas individu serta mencegah invasi-invasi organisme dan zat yang berbahaya di lingkungan yang dapat merusak dirinya (Fajarwati, 2015; Musdalipah dkk., 2018). Berdasarkan jenis kelamin, anak yang berjenis kelamin laki laki memiliki persentase sebesar 58,06 \% dibandingkan dengan perempuan sebesar 
Journal of Healthcare Technology and Medicine Vol. 6 No. 2 Oktober 2020

Universitas Ubudiyah Indonesia

e-ISSN : 2615-109X

41,94\%. Hal ini disebabkan aktivitas anak laki-laki lebih banyak dari pada anak perempuan sehingga anak laki-laki lebih banyak peluang terpaparnya agent penyakit (Sugiarti, 2015).

Antibiotik yang paling banyak digunakan pada penelitian ini adalah ceftriaxone dengan penggunaan sebanyak 54,83\% dengan lama rawat 5 hari dan yang menggunakan terapi antibiotik Ampicilin yaitu sebanyak 45,17\% dengan lama rawat 5 hari. Ceftriaxone memiliki potensi antibakteri yang tinggi, spektrum yang luas terhadap bakteri gramnegatif dan gram-positif serta memiliki potensi toksisitas yang rendah sedangkan Ampicilin memiliki mekanisme dari golongan ini adalah menghambat pertumbuhan bakteri dengan cara mengganggu protein penting untuk sintesis dinding sel bakteri (Eljaaly et al., 2019).

Leukosit atau disebut juga sel darah putih merupakan bagian terpenting dalam sistem pertahanan tubuh yang fungsinya untuk melawan sel tumor, mikroorganisme penyebab infeksi, dan zat-zat asing yang berbahaya (Bakhri, 2018). Berdasarkan tabel 4.4 pasien yang menggunakan terapi antibiotik ceftriaxone berjumlah 17 pasien, 12 diantaranya telah mencapai target terapi obat dimana kadar leukosit pasien ini normal yaitu berkisar $4.500-13.000 \mathrm{sel} / \mathrm{mm} 3$. sedangkan pasien yang menggunakan terapi antibiotik Ampicilin berjumlah 14 pasien, 12 diantaranya mencapai target leukosit normal, pada penelitian ini ada beberapa pasien dengan leukosit meningkat.

Sama halnya dengan penelitian (ida, 2010) mendapatkan leukosit tinggi pada pneunomia sekitar 74\% di akibatkan adanya bakteri pada penyakit pneumonia, penelitian (Nurrahman \& Mariyam, 2019), mengatakan ada beberapa faktor penyebab leukosit tinggi yaitu terjadinya infeksi bakteri dan jamur, stres serta radang.

Biaya medis langsung adalah biaya yang berhubungan langsung dengan perawatan kesehatan, termasuk biaya konsultasi dokter, biaya obat, biaya jasa perawat, penggunaan fasilitas rumah sakit (peralatan, kamar rawat inap), uji laboratorium dan biaya kesehatan lainnya. Dalam biaya medis langsung, selain biaya medis, terkadang diperhitungkan juga biaya non-medis seperti biaya administrasi dan biaya ambulan (Kemenkes RI, 2013).

Berdasarkan tabel 4.5 total biaya medik langsung 17 pasien yang menggunakan terapi antibiotik ceftriaxone sebesar Rp.9.761.800 dengan rata-rata biaya sebesar 574.223,52 sedang 14 pasien yang menggunakan terapi antibiotik Ampicilin sebesar 
Journal of Healthcare Technology and Medicine Vol. 6 No. 2 Oktober 2020

Universitas Ubudiyah Indonesia

e-ISSN : 2615-109X

7.973.000 dengan rata-rata biaya sebesar 569.500. Perbedaan biaya medik langsung pada pasien dikarenakan lama rawat pasien di rumah sakit, semakin lama pasien dirawat dirumah sakit maka semakin besar biaya yang yang harus dikeluarkan pasien.

Pada penelitian ini diketahui persentase aktivitas terapi antibiotik pada pasien pneumonia yang dirawat di RSUD Raden Mattaher Jambi periode Januari-Desember 2018 untuk terapi antibiotik ceftriaxone menunjukkan efektifitas sebesar 70,58\% dan Ampicilin menunjukkan efektivitas 85,71\%.

Efektivitas adalah keberhasilan pengobatan suatu obat untuk mencapai target leukosit kembali ke angka normal. Angka normal leukosit anak 4.500-13.500 sel.mm3.

ACER adalah nilai yang menyatakan jumlah biaya yang dikeluarkan untuk setiap adanya peningkatan hasil dari pengobatan. Pengobatan dengan nilai ACER terendah merupakan pengobatan yang paling cost effectiveness (Kemenkes RI, 2013).

Berdasarkan tabel 4.7 nilai ACER Ceftriaxone lebih tinggi yaitu sebesar 8.135,78 dibandingkan dengan nilai ACER ampicillin sebesar 6.644,49. Nilai dari perhitungan ACER menunjukkan bahwa setiap terjadi peningkatan $1 \%$ efektivitas dibutuhkan biaya sebesar ACER, semakin rendah nilai pada ACER dan semakin tinggi efektivitas terapi maka semakin efektif biaya terapi antibiotik tersebut, sehingga dapat disimpulkan bahwa terapi menggunakan antibiotik Ampicilin adalah obat yang paling cost-effective untuk terapi pengobatan pasien pneumonia di RSUD Raden Mattaher Jambi.

\section{KESIMPULAN}

Berdasarkan hasil penelitian, dapat disimpulkan bahwa terapi antibiotik Ampicilin merupakan terapi yang lebih cost-effective dengan persentase terapi efektivitas terapi obat yang tinggi yaitu sebesar $85,71 \%$ dan memiliki nilai ACER yang lebih rendah yaitu Rp. 6.644,49.

\section{DAFTAR PUSTAKA}

Bakhri, S. (2018). Analisis Jumlah Leukosit Dan Jenis Leukosit Pada Individu Yang Tidur Dengan Lampu Menyala Dan Yang Dipadamkan. Jurnal Media Analis Kesehatan, 1(1), 83-91. https://doi.org/10.32382/mak.v1i1.176

Eljaaly, K., Wali, H., Basilim, A., Alharbi, A., \& Asfour, H. Z. (2019). Clinical cure with ceftriaxone versus ceftaroline or ceftobiprole in the treatment of staphylococcal pneumonia: a systematic review and meta-analysis. International Journal of Antimicrobial Agents, 54(2), 149-153. https://doi.org/10.1016/j.ijantimicag.2019.05.023 
Journal of Healthcare Technology and Medicine Vol. 6 No. 2 Oktober 2020

Universitas Ubudiyah Indonesia

e-ISSN : 2615-109X

Fajarwati, A. H. (2015). Evaluasi Penggunaan Antibiotika Pada Penyakit Infeksi Saluran Pernafasan Akut Kelompok Pediatri Di Instalasi Rawat Inap Rumah Sakit Panti Rapih Yogyakarta. Universitas Sanata Dharma.

Kemenkes RI. (2013). Pedoman Penerapan Kajian Farmakoekonomi. Kementerian Kesehatan Republik Indonesia.

Musdalipah, Setiawan, M., \& Santi, E. (2018). Analisis Efektivitas Biaya Antibiotik Sefotaxime dan Gentamisin Penderita Pneumonia Pada Balita di RSUD Kabupaten Bombana Provinsi Sulawesi Tenggara. Jurnal Ilmiah Ibnu Sina, 3(1), 1-11.

Nalang, A., Citraningtyas, G., \& Lolo, W. A. (2018). Analisis Efektivitas Biaya ( Cost Effectiveness Analysis ) Pengobatan Pneumonia Menggunakan Antibiotik. PHARMACON Jurnal Ilmiah Farmasi - UNSRAT Agustus, 7(3), 321-329.

Nurrahman, N., \& Mariyam, M. (2019). Status Hematologi, Kadar IgG dan IgA Tikus yang Mengonsumsi berbagai Variasi Jumlah Tempe Kedelai Hitam. AgriTECH, 39(3), 215. https://doi.org/10.22146/agritech.26118

Riskesdas. (2013). Riset Kesehatan Dasar. https://doi.org/10.1517/13543784.7.5.803

Sugiarti, T. (2015). Studi Penggunaan Antibiotik Pada Pasien Penyakit ISPA Usia Bawah Lima Tahun Di Instalasi Rawat Jalan Puskesmas Sumbersari Periode 1 Januari-31 Maret 2014. Pustaka Kesehatan, 3(2), 5. 